\title{
Risk Management of Building Water Supply System Based on Fuzzy Analytical Hierarchy Process
}

\author{
Xiangkui Chen $^{1, \text { a }}$, Xiaojia Huang ${ }^{2, \mathrm{~b}}$, Shuibo $\mathrm{Xie}^{1, \mathrm{c}^{*}}$, Dongli $\mathrm{Wu}^{1, \mathrm{~d}}$ \\ ${ }^{1}$ School of Urban Construction, University of South China, Hengyang Hunan421001, China \\ ${ }^{2}$ China IPPR International Engineering Co., LTD, Beijing100089, China \\ a15237598059@163.com, ${ }^{\mathrm{b}} 13501165425 @ 163 . c o m,{ }^{\mathrm{C} x i e s b m r @ 263 . n e t,{ }^{d} 981635161 @ q q . c o m}$
}

Keywords: Water supply system; Risk management; Evaluation indicator; Fuzzy analytic hierarchy process

Abstract. Risk management of building water supply system is to determine the possible factors affecting normal operation of system. The fuzzy analytic hierarchy process (FAHP) based on triangle fuzzy mathematics is carried out in this paper. Safety assessment indicator system was built by literature research and questionnaires. The weight of each level relative to the target level was calculated by FAHP. The results show that the main influence factors on the safety of building water supply system are: inadequate flows, backflow and pipeline corrosion, scaling material and sediment. According to the results, Managers can take corresponding measures to reduce the risk of pipeline purposefully.

\section{Introduction}

As the basic industries of national economy and social development, water supply industry is also the public utilities. Water supply security is the important symbol of city modernization[1]. Risk management work has been gradually developed at home and abroad. The world health organization has developed a risk management as the core of water safety plan for drinking water security problems[2]. Risk management was firstly applied to urban water supply system in the 1970s, with a long history of more than 40 years. Most building water supply system is managed by untrained or lack of professional knowledge people in China[3]. Meanwhile, in the building water supply system, the security of building water supply system tend to be ignored with the separation of ownership and management.

The world health organization survey shows that at least 1.8 million people die every year from diarrhoeal disease, of which $88 \%$ is due to unsafe drinking water supply[4]. Incomplete statistics about 184 cities across the country by the Ministry of Construction illustrated that,in 2003, serious shortage of water supply pressure influenced the water supply of 26544 times, covering 20 million people. Given the importance of the safe operation of the building water supply system, the study of security management is impending.

\section{Construction of indicator system}

The construction of evaluation indicator system is the basis of building water supply system security evaluation work. The scientific rationality of indicator system must be guaranteed. In this paper, through reading lots of literatures and referring to building water supply and drainage system security evaluation criteria (draft), the standard level of building water supply system security evaluation was concluded as flows: operational safety, water quality safety, environmental safety, equipment safety, pipeline safety and manipulating safety. On this basis, through investigation and study, combining with system failures found during the running of building water supply system, we constructed the evaluation indicator system of building water supply system which is shown in table 1 . 
Table 1 Safety evaluation indicator system of water supply system

\begin{tabular}{cll}
\hline object level & standard level & measure level \\
\hline & (A1) operational safety & A11 overpressures \\
& & A12 inadequate flows \\
& A21 backflow \\
& (A2) water quality safety & A22 microbial reproduction \\
& A23 residual chlorine byproducts \\
& A24 pipeline corrosion, scaling material \\
(A) the safety of & (A3) environmental safety & A31 noise pollution \\
building water & & A32 destroy wall safe \\
supply system & A41 leakage of shaft seal \\
& & A42 motor overload \\
& & A43 unreasonable water tank design \\
& A51 pipes frozen \\
& (A5) pipeline safety & A52 pipeline leakage \\
& A53 pipeline corrosion \\
& & A54 water hammer effect \\
& (A6) manipulating safety & A61 staff \\
& A62 the rules and regulations \\
& A63 equipment maintenance \\
\hline
\end{tabular}

\section{Fuzzy Analytical Hierarchy Process}

\section{An overview of fuzzy analytic hierarchy process}

Fuzzy analytic hierarchy process is the product of fuzzy mathematics applied to analytic hierarchy process. This method is used to solve some complex problems of quantitative analysis[5]. The basic principle of FAHP, with the pairwise comparison of the influence factors, is using the triangular fuzzy number instead of the traditional AHP 1-9 scale representing the comparative result. The 1-9 scale is shown in table 2.

Table 2 1-9 scale method

\begin{tabular}{ll}
\hline \multicolumn{1}{c}{$\begin{array}{c}\text { Preferences expressed in numeric } \\
\text { variables }\end{array}$} & Preferences expressed in linguistic variables \\
\hline 1 & Equal importance \\
3 & Moderate importance \\
5 & Strong importance \\
7 & Very strong importance \\
9 & Extreme importance \\
$2,4,6,8$ & Intermediate values between \\
\hline
\end{tabular}

Although these discrete digital is simple and easy to use, the scale cannot well reflect the fuzziness of human judgment. Dutch scholar van Laarhoven et al. put forward the fuzzy judgment matrix expressed by triangular fuzzy number[6]. This method overcome the subjectivity of human mind and makes the results more reasonable. 


\section{Triangular fuzzy number}

The triangular fuzzy numbers is represented as follows:

$\tilde{\mathrm{a}}_{i j}=\left(L_{\mathrm{ij}}, M_{i j}, U_{i j}\right)$.

Where $L_{\mathrm{ij}} \leq M_{i j} \leq U_{i j}, L_{i j}, M_{i j}, U_{i j}$ respectively represent lower bound, median and upper bound.

In the application of FAHP, lower bound, median and upper bound can be expressed as follows:

$L_{\mathrm{ij}}=\min \left(a_{i j k}\right)$.

$M_{i j}=\sqrt[n]{\prod_{k=1}^{n} a_{i j k}}$.

$U_{i j}=\max \left(a_{i j k}\right)$.

Where $a_{i j k}=$ number $\mathrm{k}$ expert judge the relative importance of $A_{i}$ and $A_{j}$.

\section{The steps of fuzzy analytic hierarchy process}

(1) the development of hierarchy model

The first step in the FAHP procedure is to decompose the system into a hierarchy including the most important elements of the system. Hierarchical structure model is generally divided into three levels: object level, standard level and measure level [7].

(2) the construction of fuzzy judgement matrix

For each element of the hierarchy structure all the associated elements in low hierarchy are compared in pairwise comparison tables. Then fuzzy judgement matrix can be achieved after the results expressed by triangular fuzzy number.

(3) De-fuzzy

The method of de-fuzzy adopted in paper is put forward by literature [9]. The de-fuzzy of triangular fuzzy number $\tilde{a}_{i j}$, the value of $\left(a_{\mathrm{ij}}^{\alpha}\right)^{\lambda}$ can be got as follows:

$$
\left(\mathrm{a}_{i j}^{\alpha}\right)^{\lambda}=\left[\lambda \times L_{i j}^{\alpha}+(1-\lambda) \times U_{i j}^{\alpha}\right] .
$$

$\left(a_{i j}^{\alpha}\right)^{\lambda}=1 /\left(a_{j i}^{\alpha}\right)^{\lambda}$.

$L_{\mathrm{ij}}^{\alpha}=\left(M_{i j}-L_{i j}\right) \times \alpha+L_{i j}$.

$U_{i j}^{\alpha}=U_{\mathrm{ij}}-\left(U_{i j}-M_{i j}\right) \times \alpha$.

Where $0 \leq \alpha \leq 1,0 \leq \lambda \leq 1, \mathrm{i}<\mathrm{j}, \alpha=$ the preference coefficient, when $\alpha=0$, the uncertainty is biggest, $\lambda=$ the tolerance of decision makers, the smaller the value, the more optimistic of decision makers, whereas the decision makers more pessimistic.

\section{Check the consistency}

In this step the consistency property of matrices is checked to ensure that the judgments of decision makers are consistent. Consistency Index (CI) is calculated as: 
$C I=\left(\lambda_{\max }-n\right) /(n-1)$.

Where $\lambda_{\max }=$ maximum eigenvalue of judgement matrix, $\mathrm{n}=$ order of the matrix.

The consistency index of a randomly generated reciprocal matrix shall be called to the random index (RI), with reciprocals forced. Its value can be obtained from table 3 . The last ratio that has to be calculated is CR. Generally, if CR is less than 0.1, the judgments are consistent, so the derived weights can be used. The formulation of CR is:

$C R=C I / R I$

Table 3 The value of RI

\begin{tabular}{ccccccccc}
\hline order of matrix & 1 & 2 & 3 & 4 & 5 & 6 & 7 & 8 \\
\hline RI & 0 & 0 & 0.58 & 0.90 & 1.12 & 1.24 & 1.32 & 1.41 \\
\hline
\end{tabular}

\section{The application of fuzzy analytic hierarchy process}

\section{Construction of fuzzy judgement matrix}

The questionnaires based on the Table 1 are produced for four experts independently finishing it. In the process of implementation, fuzzy judgement matrices on different levels is established by experts through pairwise comparison of various indicators. The fuzzy judgement matrix of standard level relative to object level is shown in Table 4.

Table 4 The fuzzy judgement matrix of standard level relative to object level

\begin{tabular}{|c|c|c|c|c|c|c|}
\hline A & A1 & A2 & A3 & A4 & A5 & A6 \\
\hline A1 & $(1,1,1)$ & $\begin{array}{c}(0.14,0.21,0.33 \\
)\end{array}$ & $(2,3.13,5)$ & $(1,1.79,5)$ & $(2,3.13,5)$ & $(2,2.22,3)$ \\
\hline A2 & $(3,4.79,7)$ & $(1,1,1)$ & $\begin{array}{c}(5,5.56,7.14 \\
)\end{array}$ & $(3,4.35,5)$ & $(3,4.35,5)$ & $(5,5,5)$ \\
\hline A3 & $(0.2,0.32,0.5)$ & $(0.14,0.18,0.2)$ & $(1,1,1)$ & $(1,2.33,5)$ & $(0.5,0.84,1)$ & $(1,1.56,3)$ \\
\hline A4 & $(0.2,0.56,1)$ & $(0.2,0.23,0.33)$ & $(0.2,0.43,1)$ & $(1,1,1)$ & $(0.5,0.84,1)$ & $(2,2.7,3)$ \\
\hline A5 & $(0.2,0.32,0.5)$ & $(0.2,0.23,0.33)$ & $(1,1.19,2)$ & $(1,1.19,2)$ & $(1,1,1)$ & $(3,3.45,5)$ \\
\hline A6 & $\begin{array}{c}(0.33,0.45,0.5 \\
)\end{array}$ & $(0.2,0.2,0.2)$ & $\begin{array}{c}(0.33,0.64,1 \\
)\end{array}$ & $\begin{array}{c}(0.33,0.37,0.5 \\
)\end{array}$ & $\begin{array}{c}(0.2,0.29,0.33 \\
)\end{array}$ & $(1,1,1)$ \\
\hline
\end{tabular}

Due to the same principle and space problem, The fuzzy judgement matrix of measure level(A11,A12) relative to standard level(A1) is listed in table 5.

Table 5 The fuzzy judgement matrix of measure level (A11, A12) relative to standard level (A1)

\begin{tabular}{lll}
\hline A1 & A11 & A12 \\
\hline A11 & $(1,1,1)$ & $(3,3.41,5)$ \\
A12 & $(0.2,0.29,0.33)$ & $(1,1,1)$ \\
\hline
\end{tabular}

\section{De-fuzzy}

The judgement matrices can be achieved after the de-fuzzy of the above fuzzy judgement matrices according to the formula (5) and (6), as shown in table $4^{*}$ and $5^{*}$. 
Table $6^{*}$ The judgement matrix of standard level relative to object level

\begin{tabular}{|c|c|c|c|c|c|c|c|}
\hline A & A1 & $\mathrm{A} 2$ & A3 & A4 & A5 & A6 & weight \\
\hline A1 & 1 & 0.20 & 2.94 & 1.72 & 2.94 & 2.27 & 0.182 \\
\hline A2 & 4.9 & 1 & 5.56 & 4 & 4 & 5 & 0.464 \\
\hline A3 & 0.34 & 0.18 & 1 & 1.92 & 0.74 & 1.52 & 0.091 \\
\hline A4 & 0.58 & 0.25 & 0.52 & 1 & 0.74 & 2.5 & 0.091 \\
\hline A5 & 0.34 & 0.25 & 1.35 & 1.35 & 1 & 3.57 & 0.116 \\
\hline A6 & 0.44 & 0.2 & 0.66 & 0.40 & 0.28 & 1 & 0.056 \\
\hline \multicolumn{2}{|c|}{$\lambda \max =6.402$} & \multicolumn{2}{|c|}{$\mathrm{CI}=0.080$} & \multicolumn{2}{|c|}{$\mathrm{RI}=1.24$} & \multicolumn{2}{|c|}{$\mathrm{CR}=0.065$} \\
\hline
\end{tabular}

Table $7^{*}$ Judgement matrix of measure level (A11, A12) relative to standard level (A1)

\begin{tabular}{llll}
\hline A1 & A11 & A12 & weight \\
\hline A11 & 1 & 3.70 & 0.212 \\
A12 & 0.27 & 1 & 0.787 \\
$\lambda \max =1.9995$ & $\mathrm{CI}=0$ & $\mathrm{RI}=0$ & $\mathrm{CR}=0$ \\
\hline
\end{tabular}

\section{Check the consistency and the total sequencing}

The MATLAB software is used to calculate the weight of judgement matrix in this paper. According to the calculation results, the judgement matrix has satisfactory consistency (CR is less than 0.1). The results are shown in table $4^{*}$ and $5^{*}$. The total sequencing is calculated by combination of corresponding weight. The relative weights of all indicators are shown in table 6 .

Table 8 The relative weights of all indicators

The weight of standard level relative to object level

A1 operational safety $(0.182)$

A2 water quality safety (0.464)

A3 environmental safety $(0.091)$

A4 equipment safety (0.091)

A5 pipeline safety $(0.116)$

A6 manipulating safety (0.056)
The weight of measure level relative to standard level
The weight of measure level relative to object level

0.039

A11 overpressures (0.212)

0.143

A12 inadequate flows (0.787)

0.272

0.049

A22 microbial reproduction (0.106)

0.041

0.102

A24 pipeline corrosion, scaling material and sediment (0.219)

A31 noise pollution (0.847)

0.077

0.014

0.010

A41 leakage of shaft seal(0.114)

0.027

A42 motor overload (0.300)

0.053

0.010

0.051

0.017

0.038

0.010

0.030

0.016 


\section{Conclusions}

1 During the operation of building water supply system, the scientific evaluation indicator system is constructed through statistics and analysis of the system failure.

2 The fuzzy analytic hierarchy process (FAHP) is used to overcame the limitations of the analytic hierarchy process (AHP) and ensure the objectivity and certainty of indicator weight.

3 the main factors affecting safe operation of building water supply system are inadequate flows(A12), backflow(A21) and pipeline corrosion, scaling material and sediment(A24). Meanwhile, the corresponding control measures are made for different conditions as follows:

(1) Inadequate flows: inadequate flows of building water supply system are not depending only on insufficient pressure of municipal pipe network. Pipeline leakage would affect the water supply pressure of residential areas and waste water resources. In another aspect, pipe scaling would pose the decrease of the flow section of original design, thus the conveyance capacity of water pipe decreases. In the process of inspection for water system maintenance, managers should timely repair pipe leakage and replace or clean blocked pipeline.

(2) Backflow: the outlet of pipe not be submerged by impurities and liquids should be paid attention by managers. Meanwhile, we should check termly running condition of the attachment such as vacuum breaker or anti-backflow equipment which is installed on pipeline to prevent backflow.

(3) Pipeline corrosion, scaling material and sediment: the scaling and sediment appeared on the inner wall of water supply pipes after running for a long time. Cleaning the water supply pipes regularly is necessary to increase the operation efficiency of water system. The water quality monitoring system should be established to collect the basic operation data and the corresponding strategy can be taken as early as possible to control the deterioration of water quality.

\section{References}

[1] Yazhen Zhou, Yunlong Cai, Yin Liu, Risk assessment and safety management research of urban water supply system[J].Water and Wastewater Engineering,2013,12:13-16+11-12.(In Chinese)

[2] J. Bartram, L. Corrales, A. Davison. Water safety plan manual: step-by-step risk management for drinking water suppliers[M].Geneva: World Health Organization,2009: 1-101

[3] David Cunliffe, Jamie Bartram, Emmanuel Briand. Water safety in buildings. Switzerland: WHO Press.2011.

[4] World Health Organization World Plumbing Council. Health aspects of plumbing . Switzerland: WHO Press.2006.

[5] L.G. VARGAS, T.L. SAATY, Models, methods, concepts and applications of the analytic hierarchy process. Kluwer Academic Publishers.2000.

[6] P. J .M. Van Laarhoven, W.A. Pedrycz, fuzzy extension of Saaty's priority theory[J].Fuzzy Sets and Systems, 1983,11(3):229-241.

[7] Yunli Yuan. The research on the construction engineering project risk management based on fuzzy analytic hierarchy process [M].Chongqing University, 2013. (In Chinese)

[8] T. S. LIOU, M. J. J. WANG. Ranking fuzzy numbers with integral value [J]. Fuzzy Sets and Systems, 1992,50(3):247-255. 